\title{
Sensorineural hearing loss and language development following neonatal extracorporeal
}

membrane oxygenation.

Desiree van den Hondel ${ }^{1}$, Marlous J Madderom ${ }^{1}$ MSc, Andre Goedegebure ${ }^{2}$ PhD, Saskia J Gischler ${ }^{1}$ MD PhD, Petra Mazer ${ }^{1}$ PhD, Dick Tibboel ${ }^{1}$ MD PhD, Hanneke IJsselstijn ${ }^{1}$ MD PhD

${ }^{1}$ Intensive Care and Department of Pediatric Surgery

${ }^{2}$ Department of Audiology-ENT

Erasmus MC - Sophia Children's Hospital, Rotterdam, the Netherlands

Address for correspondence:

Hanneke IJsselstijn, M.D., Ph.D.

Erasmus MC, Sophia Children's Hospital

Room Sk-1280, P.O. Box 2060, 3000 CB, Rotterdam, the Netherlands

Fax: $\quad+31(0) 10-7036288$

Phone: $\quad+31(0) 10-7036203$

E-mail: h.meijers-ijsselstijn@erasmusmc.nl

Keywords: congenital diaphragmatic hernia, audiometry, language development

No potential conflict of interest to report.

Swart-van Essen Fund provided an unrestricted grant.

No reprints available. 


\section{Abstract}

OBJECTIVE: To determine the prevalence of hearing loss in school-age children who have undergone neonatal extracorporeal membrane oxygenation (ECMO) treatment and to identify any effects of hearing loss on speech- and language development.

DESIGN: Prospective longitudinal follow-up study within the framework of a structured post-ECMO follow-up program.

SETTING: Outpatient clinic of a level III university hospital.

RESULTS: Tone audiometry was performed by standardized protocol in 136 children aged 5 to 12 years. Hearing loss was considered clinically significant when $>20 \mathrm{~dB}$. Hearing was normal in $75.7 \%$ of children. Five children (3.7\%) had bilateral sensorineural or combined hearing loss; 3 of them received special audiological care (2.2\% of total sample). Of the 24 children with congenital diaphragmatic hernia, $19(79.2 \%)$ had normal hearing; and only $2(8.3 \%)$ had mild SNHL, unilateral in one of them. Follow-up at 24 months of age had shown normal verbal and non-verbal developmental scores. Language development and intelligence median (range) scores at 5 years of age were also normal: receptive language development 104 (55-133); syntactical development 104 (68-132); and lexical development 101 (50-141) for 89 children; intelligence quotient was 104 (68-132) in 106 children. Scores did not differ between those with normal hearing, and those with mild hearing loss, or those with moderate to severe hearing loss $(p=0.800, p=0.639, p=0.876$, and $p=0.886$, for the respective developmental tests).

CONCLUSIONS: We found normal language development and intelligence in a cohort of neonatal ECMO survivors. The prevalence of bilateral sensorineural hearing loss was in accordance with that of larger series in the United States - which exceeds the prevalence in the normal population. 


\section{Introduction}

Extracorporeal membrane oxygenation (ECMO) is a supportive intensive-care technique to counteract acute reversible cardiorespiratory failure. ECMO provides prolonged cardiopulmonary bypass while allowing the lungs to rest using minimal ventilator settings (1). A trial in critically ill neonates conferred a survival advantage of ECMO over conventional management - except in cases of congenital diaphragmatic hernia $(\mathrm{CDH})$ - without a concomitant increase in severe disability (2).

Sensorineural hearing loss (SNHL) is one of the disabilities reported in patients who have undergone ECMO-treatment (3-5). It was found in 28 of 371 ECMO-survivors (7.5\%) from 6 different centers in North America (6), Frequencies per center ranged from 3 to 21\%; follow-up from 1-10 years. Several groups have reported delayed onset of SNHL and therefore advocated ongoing follow-up testing $(4,5$, 7). A number of risk factors for SNHL after neonatal intensive care have been identified: presence of $\mathrm{CDH}(7)$, prolonged ventilatory support $(8,9)$ prolonged $\operatorname{ECMO}(7,10)$, sepsis or bacterial meningitis $(8,11)$, prolonged administration of aminoglycosides $(7)$, severe birth asphyxia $(9,11)$, cerebral bleeding or cerebral infarction(11), and clinical seizures prior to ECMO treatment (10). Infants with hearing loss $(\mathrm{HL})$ are at risk for delayed speech development and language acquisition, impaired academic achievement, and social/ emotional developmental problems (12, 13). Early identification of $\mathrm{HL}$ and appropriate intervention could prevent or minimize adverse effects on these developmental areas $(14,15)$. To our knowledge only one study - by Desai et al. - explored the relationship between hearing loss and language development of ECMO survivors; the relationship between neonatal brainstem audiometry results and delayed receptive language ability proved uncertain (16). To shed more light on this issue we tested hearing as well as speech- and language development in survivors of neonatal ECMO-treatment. The following research questions were addressed: 1) What is the prevalence of SNHL after neonatal ECMO treatment?; 2) Does HL affect speech- and language development and intelligence? 


\section{Participants and methods}

Participants

A cohort of children, now aged between 5 and 12 years, who had received neonatal veno-arterial (VA) ECMO support between January 1992 and February 2005, and mainly consisting of children living in the referral area of the Erasmus MC-Sophia Children's Hospital, Rotterdam, the Netherlands I. The large majority had been treated in this hospital an additional four in the Radboud University Nijmegen Medical Center (Nijmegen, the Netherlands), and one in the University Hospitals Leuven (Leuven, Belgium). Inclusion criteria and treatment protocols did not differ between these centers. ECMO was initiated in case of reversible severe respiratory failure and an estimated mortality risk of higher than $80 \%$ using the entry criteria reported by Stolar et al. (17).

Entry criteria and exclusion criteria were previously described by our group (18) and did not change during the study period. Cerebral ultrasound examinations were performed prior to treatment with ECMO, daily during ECMO treatment, and before discharge from our hospital. All subjects of the study reported here participate in a prospective post-ECMO follow-up program that provides for regular assessments of lung function, growth and developmental parameters until 18 years of age (19). Based on the national consensus on neonatal follow-up and the Dutch Ministry of Health's requirement to provide relevant data, the assessment protocol is the standard of care following ECMO treatment. As a consequence IRB approval was waived. Parents of all children studied were informed about the study and gave written informed consent to evaluate data collected during routine care.

Procedures and study design

The following clinical characteristics were recorded prospectively: underlying condition, gestational age, birth weight, age at onset of ECMO, duration of ECMO support, mean airway pressure (MAP) and highest oxygenation index $(\mathrm{OI})$ prior to ECMO, duration of mechanical ventilation before ECMO, total duration of mechanical ventilation (including ECMO), duration of oxygen dependency, and prevalence of chronic lung disease (CLD). CLD was defined as oxygen dependency at day 28 (20). The assessment protocol encompasses hospital consultations at 6, 12, 24 months and 5, 8 and 12 years of age. Audiometry is routinely performed at 5 years of age. However, because the program started in 2001, some children entered not until 8 or 12 years of age. In those cases audiometry was performed during their first visit (Figure 1). 
Hearing assessment

Audiometry was performed with a Madsen clinical audiometer (OB822; Madson Electronics, Denmark) according to the standard procedure used in the Netherlands, including both air conduction and bone conduction measurements. Tympanometry was done with an Interacoustics AT $235 \mathrm{~h}$ device (Interacoustics USA, Eden Prairie, Minnesota), with a 226-Hz probe stimulus.

Assessment of language development and intelligence

Within the framework of the follow-up program, the Dutch translation of the Bayley Developmental Scales (BOS 2-30) had been administered at age 2 years. This standardized instrument assesses both verbal and non-verbal development of 2 to 30-month-old children (21). From December 2003, a new version of the BOS 2-30 was used: the Bailey Scales of Infant Development - Second Edition Dutch version (BSID-II-NL) (22). The BOS 2-30 and the BSID-II-NL share the same background and are substantially related to each other (22). The BSID-II-NL was administered to 8 children.

At 5 years of age the Reynell Test (receptive language development), the Schlichting Test (syntactical and lexical expression), and the short version of the Revised Amsterdam Intelligence Test were administered to assess language development and intelligence, as described previously (19).

\section{Data analysis}

Hearing assessment

In consultation with the audiologist (A.G.) the audiograms were interpreted as follows. Two frequency bands were distinguished: low and high. For the low frequency band the mean $\mathrm{HL}$ was calculated at 500,1000 and $2000 \mathrm{kHz}$; for the high frequency band at 2000, 4000 and $8000 \mathrm{kHz}$. HL severity was categorized in terms of clinical consequences. $\mathrm{HL}<20 \mathrm{~dB}$ is "not significant", thus "normal"; $20-40 \mathrm{~dB}$ is "mild"; and $>40 \mathrm{~dB}$ is "moderate to severe".

$\mathrm{HL}$ was considered symmetrical if it was of the same category in both ears for both frequencies.

We distinguished between "conductive HL" (>10 dB difference between the bone conduction response and the air conduction response) and "SNHL only" (difference $\leq 10 \mathrm{~dB}$ ). If both were present HL was labelled as: combined. Tympanometry was used to confirm conductive HL. 
Language development and intelligence

Language developmental and intelligence scores below 85 (<-1 SD) were categorized as "below average"; scores between 85 and 115 ( $\geq-1$ SD and $\leq+1$ SD) as "average"; and scores above 115 (>+1 SD) as "above average".

Statistical methods

Group comparisons were tested with the Kruskal-Wallis $\mathrm{H}$ test. The Mann-Whitney test with Bonferroni correction was used for post-hoc analysis. Proportions were compared using the Chi-square test. Data on $\mathrm{HL}$ and developmental tests for two subgroups - underlying condition $\mathrm{CDH}$ or meconium aspiration syndrome (MAS) - were analyzed separately. These two subgroups were considered of special interest. $\mathrm{CDH}$ is associated with abnormal lung development with severe pulmonary hypertension and increased prevalence of $\mathrm{HL}(7,23,24)$; infants with MAS form the largest homogeneous subgroup of children treated with ECMO. The other subgroups are small and more heterogeneous with respect to underlying disease. Data are presented as mean (SD) or median (range). Statistical significance was accepted at a two-sided 5\% level for all tests. Statistical analyses were performed using SPSS 17.0 for Windows. 


\section{Results}

Between January 1992 and February 2005 a total of 257 neonates received ECMO in our center and 5 children from our referral area elsewhere; 76 patients died at neonatal age $(29 \%$; CDH n=46 (61\%)). Of the remaining patients, 34 did not participate in the follow-up program (parents' refusal $n=17$; other reasons $n=17$ ), and 13 did not undergo audiometry for different reasons (Figure 1). One of them, a girl who had suffered from severe birth asphyxia, had been diagnosed with severe bilateral SNHL at the age of 6 months and wore hearing aids. She was evaluated elsewhere. Two other children who had been evaluated elsewhere had normal hearing. In 8 others who were not tested $(7$ for practical reasons and 1 with Down syndrome and ENT follow-up elsewhere) HL was not suspected by members of the follow-up team or the parents. Information on $\mathrm{HL}$ was lacking in the 2 remaining children: One was suffering from mental retardation and autism and lacked cognitive ability for audiometry; one, seen at age 5 years before audiometry was introduced into our program, had died of multiple congenital anomalies before the next scheduled visit.

Thus, 139 children underwent audiometry. We excluded the results of three 5-year-old participants because they could not be tested reliably (Figure 1). Therefore, the results of 136 children were analyzed; 104 of them (76\%) were tested at age 5 years, $20(15 \%)$ at 8 years, and $12(9 \%)$ at 12 years.

Data on language development and intelligence at age 5 years had not been obtained in 28 children born before 1996 (because the follow-up program started in 2001) and in two 5-year-olds born after 1996 (due to parental refusal). Thus, developmental evaluation at 5 years was performed in 106 children (audiometry in 104 because in 2 of them audiometry was performed at 8 years); for 66 of these children developmental data at 2 years were also available. The Reynell receptive language development test and the Schlichting subtests for syntactical and lexical development were not administered to 17 children (practical reasons $n=10$; poor cognitive competence $n=3$; insufficient command of the Dutch language $n=3$; and language development tested elsewhere $n=1$ ). Of these 17 children, 12 had normal hearing, 2 had moderate to severe unilateral HL (one sensorineural and one conductive), 1 had mild conductive unilateral $\mathrm{HL}$ and 2 had mild conductive bilateral HL. For 7 children tested at 5 years a reliable intelligence score could not be calculated (poor cognitive competence $n=5$; recent assessment elsewhere with intelligence within normal range $n=1$; assessment with non-verbal test due to hearing problems with intelligence in normal range $n=1$ ). 
Table 1:

Baseline and ECMO characteristics of participants

\begin{tabular}{|c|c|}
\hline & $n=136$ \\
\hline Boys/girls, $\mathrm{n}(\%)$ & $73 / 63(54 / 46)$ \\
\hline \multicolumn{2}{|l|}{ Diagnosis, $\mathrm{n}(\%)$} \\
\hline $\mathrm{CDH}$ & $24(18)$ \\
\hline MAS & $73(54)$ \\
\hline Other & $39(29)$ \\
\hline Gestational age, wks, mean (SD) & $39.6(1.8)$ \\
\hline Birth weight, kg, mean (SD) & $3.37(0.57)$ \\
\hline Age at start ECMO, hrs, median (range) & $25(4-600)$ \\
\hline Oxygenation index prior to ECMO, median (range) & $43(13-130)$ \\
\hline Highest mean airway pressure, $\mathrm{cm} \mathrm{H}_{2} \mathrm{O}$, median (range) & $20(11-45)$ \\
\hline Time on ECMO, hrs, median (range) & $133(47-510)$ \\
\hline Duration of ventilation including ECMO, $d$, median (range) & $12(2-130)$ \\
\hline \multicolumn{2}{|l|}{ Oxygen requirement post extubation, $\mathrm{n}(\%)$} \\
\hline 1 day-1 wk & $54(40)$ \\
\hline $1 \mathrm{wk}-1 \mathrm{mo}$ & $50(37)$ \\
\hline$>1 \mathrm{mo}$ & $18(13)$ \\
\hline Unknown & $14(10)$ \\
\hline \multicolumn{2}{|l|}{ Chronic lung disease, $\mathrm{n}(\%)$} \\
\hline no & $100(74)$ \\
\hline yes & $27(20)$ \\
\hline unknown & $9(7)$ \\
\hline
\end{tabular}

$\mathrm{CDH}$ = congenital diaphragmatic hernia; MAS = meconium aspiration syndrome; remaining diagnoses consist of: persistent pulmonary hypertension $n=18$, sepsis $n=8$, pneumonia $n=4$, birth asphyxia $n=2$, cardiac disease $n=2$, other $n=3$. Chronic lung disease was defined as oxygen dependency at day 28 . 
The baseline characteristics of all participants are shown in Table 1. None of the baseline characteristics differed between children included in the analysis and those who were excluded or lost to follow-up (data not shown). The subgroup of 106 children who underwent developmental assessment at 5 years did not differ from the total study group (data not shown).

Of the 136 children tested audiologically, $103(75.7 \%)$ had normal hearing and $33(24.3 \%)$ had a significant HL. Eleven children had SNHL only (8.1\%); one child suffered from combined HL $(0.7 \%)$; the remaining 21 children (15.4\%) had conductive HL.

Five children had bilateral SNHL (3.7\% of the study population); in 2 of them (1.5\%) SNHL was mild, symmetrical, and of high frequencies only. Three children (2.2\%) had moderate to severe bilateral SNHL, symmetrical in 2 of them, with loss of both high and low frequencies. The characteristics of these 5 children are described in Table 2. All had normal cerebral ultrasound during ECMO treatment. Three needed special education; 2 of them for learning difficulties (Patient 1 with severe birth asphyxia and Patient 2 with mental retardation due to a partial chromosome X-duplication), and one for hearing problems (Patient 4). The other 2 children received regular education with extra support for hearing problems and attention deficit disorder (Patient 3) or language support (Patient 5, who was not a native Dutch speaker).

SNHL in the remaining 7 children (5.1\%) was unilateral; in 2 children it had resolved at follow-up. In 2 of the other 5 it was mild, but 3 children (2.2\% of the study population) had completely impaired hearing in one ear (ipsilateral cerebral infarction $n=1$; bacterial meningitis at age 1 month $n=1$; unknown cause $n=1$ ). All three had abnormal audiological examinations within the first months of life and HL had been diagnosed early. The patient with bacterial meningitis suffered from severe combined HL.

Table 2: Characteristics of five children with bilateral sensorineural hearing loss. 


\begin{tabular}{|c|c|c|c|c|c|}
\hline & Patient 1 & Patient 2 & Patient 3 & Patient 4 & Patient 5 \\
\hline \multicolumn{6}{|l|}{ Hearing loss } \\
\hline \multirow[t]{4}{*}{ Description } & Right ear: $40 \mathrm{~dB}$ at 4 & $70 \mathrm{~dB}$ at $8 \mathrm{kHz}$ & $20 \mathrm{~dB}$ at $250 \mathrm{~Hz}$ & $30-50 \mathrm{~dB}$ at 250 & Max. $30 \mathrm{~dB}$ \\
\hline & $\mathrm{kHz}, 80 \mathrm{~dB}$ at $8 \mathrm{kHz}$ & & $40-70 \mathrm{~dB}$ at 500 & $\mathrm{~Hz} ; 70-100 \mathrm{~dB}$ at & \\
\hline & left ear: cup-shaped & & $\mathrm{Hz}-8 \mathrm{kHz}$ & $500 \mathrm{~Hz}-8 \mathrm{kHz}$ & \\
\hline & $\mathrm{HL} 45 \mathrm{~dB}$ at $2 \mathrm{kHz}$ & & & & \\
\hline \multirow[t]{2}{*}{ Neonatal screening } & NA; brainstem & NA & Abnormal & Normal & $?$ \\
\hline & normal at 5 yrs & & & & \\
\hline Age diagnosis $\mathrm{HL}$ & $8.0 \mathrm{yrs}$ & $8.0 \mathrm{yrs}$ & 0.2 yrs & $1.1 \mathrm{yrs}$ & 5.3 yrs \\
\hline \multicolumn{6}{|l|}{ Risk factors } \\
\hline Diagnosis & Severe asphyxia & $\mathrm{CDH}$ & MAS, asphyxia & PPHN & MAS \\
\hline Comorbidity & Pre-ECMO seizures & - & - & - & - \\
\hline \multirow[t]{5}{*}{ Medication } & Furosemide & Phenobarbital & Furosemide & Furosemide & Furosemide \\
\hline & Phenobarbital & & continuously & Phenobarbital & \\
\hline & Tobramycin (single & & Phenobarbital & Vancomycin & \\
\hline & dose) & & Erythromycin & & \\
\hline & & & fluconazol & & \\
\hline Age start ECMO & 25 hours & 20 hours & 9 hours & 284 hours & 27 hours \\
\hline ECMO duration & 96 hours & 120 hours & 184 hours & 288 hours & 137 hours \\
\hline Ventilation duration & 12 days & 37 days & 22 days & 36 days & 9 days \\
\hline \multicolumn{6}{|l|}{ Outcome } \\
\hline Hearing aids & No & No & Yes & Yes & No \\
\hline \multirow[t]{2}{*}{ Speech therapy } & At 8 yrs & At 8 yrs & At 2 (articulation) & At 5 yrs & None \\
\hline & & & and 5 yrs & & \\
\hline Language & Below average* & Below average* & Average & Average & Below average \\
\hline \multicolumn{6}{|l|}{ development } \\
\hline Intelligence (IQ) & $62^{*}$ & $62^{*}$ & 85 & 99 & 74 \\
\hline
\end{tabular}

$\mathrm{CDH}$ : congenital diaphragmatic hernia; MAS: meconium aspiration syndrome; PPHN: persistent pulmonary hypertension of the newborn; CLD: chronic lung disease; ADHD: attention deficit hyperactivity disorder; NA: not available, i.e. not performed; language development measured with the Reynell and Schlichting language tests; IQ: intelligence quotient measured with the RAKIT intelligence test,. * Assessment at 8 yrs (born before 1996): language development at 8 years measured with verbal subtests of the Wechsler Intelligence Scale.

Hearing was normal in 19 of the $24 \mathrm{CDH}$ patients (79.2\%); only 2 of the $24 \mathrm{CDH}$ patients $(8.3 \%)$ had mild SNHL, which was unilateral in one of them. The other $3 \mathrm{CDH}$ patients had conductive HL. The 
proportions of children with normal hearing, SNHL or conductive HL did not differ between the three diagnosis categories $(p=0.84$, Chi-square test).

At 2 years of age the median verbal and non-verbal developmental scores were in the normal range (Table 3). The verbal developmental scores differed between children with normal hearing, mild hearing loss, and moderate to severe hearing loss ( $p=0.028$; Kruskal-Wallis H-test). Post-hoc testing revealed that the verbal developmental score for children with a normal hearing was significantly lower than that for children with mild hearing loss ( $p=0.007$; Mann-Whitney test). The non-verbal scores did not differ between the three hearing groups ( $p=0.363$; Kruskal-Wallis $\mathrm{H}$-test). The results are shown in Table 3.

At 5 years of age the median language and intelligence scores were in the normal range (Table 3 ). Receptive language development, syntactical language expression and lexical language expression did not differ between children with normal hearing, mild hearing loss, and moderate to severe hearing loss $(p=0.800, p=0.639, p=0.876$, respectively; Kruskal-Wallis H-test). The same was true for intelligence $(p=0.886$; Kruskal-Wallis H-test). 
Table 3 Developmental results at 2 and 5 years following neonatal ECMO

\begin{tabular}{|c|c|}
\hline 2 years & Median (range) \\
\hline Verbal score $(n=66)$ & $\underline{98(50-136)}$ \\
\hline Mild hearing loss $(n=13)$ & $118(51-134)$ \\
\hline Moderate to severe hearing loss $(n=5)$ & $96(65-136)$ \\
\hline Normal hearing $(n=48)$ & $94(50-134)^{*}$ \\
\hline$\underline{\text { Non-verbal score }(n=66)}$ & $106(48-133)$ \\
\hline Mild hearing loss $(n=13)$ & $112(60-130)$ \\
\hline Moderate to severe hearing loss $(n=5)$ & $92(64-133)$ \\
\hline Normal hearing $(n=48)$ & $103(48-132)$ \\
\hline \multicolumn{2}{|l|}{5 years } \\
\hline Reynell ( $n=89)$ & $\underline{95(56-138)}$ \\
\hline Mild hearing loss $(n=18)$ & $99(56-127)$ \\
\hline Moderate to severe hearing loss $(n=4)$ & $99(85-108)$ \\
\hline Normal hearing $(n=67)$ & $95(62-138)$ \\
\hline$\underline{\text { Schlichting syntactical language expression }(n=89)}$ & $\underline{101(50-141)}$ \\
\hline Mild hearing loss $(n=18)$ & $107(55-122)$ \\
\hline Moderate to severe hearing loss $(n=4)$ & $95(84-115)$ \\
\hline Normal hearing $(n=67)$ & $101(50-141)$ \\
\hline$\underline{\text { Schlichting lexical language expression }(n=89)}$ & $104(55-133)$ \\
\hline Mild hearing loss $(n=18)$ & $112(67-121)$ \\
\hline Moderate to severe hearing loss $(n=4)$ & $101(96-119)$ \\
\hline Normal hearing $(n=67)$ & $102(55-133)$ \\
\hline Intelligence quotient ( $\mathrm{n}=99$ ) & $\underline{104(68-132)}$ \\
\hline Mild hearing loss $(n=20)$ & $115(68-131)$ \\
\hline Moderate to severe hearing loss $(n=5)$ & $107(90-132)$ \\
\hline Normal hearing $(n=74)$ & $103(69-132)$ \\
\hline
\end{tabular}

*significantly lower than scores in children with mild hearing loss $(p=0.007$; Mann-Whitney test $)$ 


\section{Discussion}

In this study we found that $75.7 \%$ of children had normal hearing 5 to 12 years after neonatal VAECMO treatment; $15.4 \%$ of children had conductive HL. SNHL was established in 12 of the 136 children (8.8\%). SNHL was bilateral in 5 (3.7\%); three of them wore hearing aids and/or received special audiological care ( $2.2 \%$ of the total sample). Overall, the children's language development and intelligence at 2 and 5 years were normal. Language development and intelligence results of children with $\mathrm{HL}$ were not worse than those of children with normal hearing.

Few epidemiologic data on hearing impairment in the normal pediatric population are available. In the United States it is estimated to occur in 1.1 per 1000 infants (25); a study in the Netherlands found that 0.78 per 1000 infants had permanent hearing impairment (13). Recently, Cone and co-workers reported a $0.88 \%$ prevalence of SNHL in primary school-aged children (26). In 2009, Mehra and coworkers concluded from audiometric screening studies that $3.1 \%$ of children and adolescents in the United States suffer from unilateral or bilateral hearing impairment ( $>20 \mathrm{~dB})$. Those screening studies took place between 1958 and 1993 and most children were between 6 and 19 years old(25). We found an eightfold higher prevalence of $\mathrm{HL}(24.3 \%)$, mainly of conductive origin. A high prevalence of conductive $\mathrm{HL}$ within the first 24 months of life has been reported in very low birth weight infants, especially in those with chronic lung disease (up to $54.5 \%$ ) (27). Nasally-placed tubes for ventilatory assistance and disturbed local immunity might be associated with chronic otitis media with effusion in infants up to two years of age(28). Although all of our patients had been ventilated neonatally, it is unclear whether nasal tube placement and discturbed immunity explain our results at the age of 5 years, because our population was not born prematurely and the prevalence of conductive HL seems to decrease with age. Another possible explanation is that the 5 -year-old children in our study may have suffered from recurrent respiratory tract infections with concomitant conductive HL. However, all these assumptions are speculative and do not seem to fully explain the discrepancy in findings. Further evaluation by ENT-surgeons will be needed to uncover the origin and clinical course of conductive $\mathrm{HL}$ in ECMO-treated patients.

Regarding SNHL, Cheung and Robertson (6) reported a 7.5\% overall prevalence of SNHL in ECMO survivors, ranging from 3 to $21 \%$ in six different ECMO centers in the United States. All reviewed 13 
studies had been published before 1996. Fligor and co-workers found a $26 \%$ prevalence of bilateral SNHL in ECMO survivors born between 1986 and 1994 (7). Almost half of the children had delayedonset SNHL, and $72 \%$ had progressive HL. Cheung and co-workers also reported normal clinical neonatal screening results in children who developed SNHL. The prevalence of bilateral SNHL in our population is in accordance with data published on larger series in the United States $(29,30)$. One child with severe bilateral SNHL, who would have been eligible for the follow-up program, was evaluated elsewhere and her data had been excluded from our analysis. Should we have included her data, the prevalence of SNHL would have been $9.5 \%$ (13 of 137 cases) with bilateral $\mathrm{HL}$ in $4.4 \%$ (6 of 137 children).

In our study neonatal screening data were not available for 3 of 5 children with bilateral SNHL. One child failed to pass the neonatal screening and was referred for audiological care at an early stage. In one child who passed the neonatal screening test successfully, SNHL was diagnosed at 13 months, indicating delayed-onset SNHL.

A high prevalence of SNHL has been reported in children with $\mathrm{CDH}$, even those not treated with $\operatorname{ECMO}(7,23,24)$. Two of the $24 \mathrm{CDH}$ patients in our study had mild SNHL (one patient with bilateral HL also had a partial chromosome X duplication). Similarly, Morando and co-workers (31) reported one patient with SNHL in a cohort of $26 \mathrm{CDH}$ survivors not treated with ECMO. $\mathrm{CDH}$ is not the only risk factor for SNHL after ECMO treatment. Other reported factors are: treatment with aminoglycosides(7, 32), furosemide, muscle relaxants (32), initiation of ECMO-treatment after $>160$ hours (7), prolonged ECMO treatment, and pre-ECMO seizures(10) A nationwide study in the Netherlands revealed that the only independent risk factors for $\mathrm{HL}$ in neonates receiving intensive care were severe birth asphyxia and assisted ventilation for $\geq 5$ days (9). The small number of children with bilateral SNHL in the present study did not allow for multivariate analysis. Yet, all 5 patients with bilateral SNHL had between 2 and 5 of the above-mentioned risk factors.

All our patients were treated with VA-ECMO. During this procedure deoxygenated blood is removed from the right internal jugular vein and oxygenated blood is returned through a cannula placed in the right carotid artery. Veno-venous (VV) ECMO is a technique that has now gained more acceptance also in our institution - for use in patients with an isolated pulmonary disease without the need for cardiac support(33). Using this technique, the carotid artery need not be sacrificed and the normal 14 
pulsatility to the systemic flow is maintained. The risk for central nervous system complications (bleeding, microthrombi or infarct) seems to be less in VV-ECMO than in VA-ECMO(33). The question is whether VV-ECMO could have reduced the prevalence of SNHL. Significant differences in mean cerebral blood flow velocities between VV- and VA-ECMO have been reported. with higher blood flow velocities in the basilar artery during VA-ECMO(34). This observation seems to contradict the hypothesis that VA-ECMO has a negative influence on cochlear perfusion. Taking into account that the etiology of SNHL in ECMO-treated patients is unclear and that many different factors may play a role, we assume that VV-ECMO likely would not have reduced HL prevalence. However, additional studies are needed to confirm this assumption.

In the present study, results of language development and intelligence testing after neonatal ECMO treatment were favorable. Developmental test results of children with impaired hearing did not differ from those of children with normal hearing. Because children with unilateral HL may suffer from conductive hearing impairment in their best ear during upper airway infections, we related the developmental data to $\mathrm{HL}$ severity and not to $\mathrm{HL}$ laterality or origin. However, the small number of patients with HL does not allow for conclusions on the impact of early HL. Others have found that even mild bilateral $\mathrm{HL}$ compromises the development of language, communication skills and behavior at school age $(35,36)$. It seems, therefore, to be important to detect $H L$ at an early stage and provide early intervention.

For the main purpose of this study we described the characteristics of 5 children with purely bilateral SNHL (Table 2). Interestingly, two with profound SNHL diagnosed at an early age (at 0.2 years and 1.1 years respectively; patients 3 and 4 in Table 2) and wearing hearing aids showed normal intelligence and language development. The other three children had been diagnosed later, and showed worse intelligence and language development. In all three, however, language development and/or intelligence might have been affected by comorbidity: Two had an underlying problem associated with impaired intelligence: severe birth asphyxia (patient 1; Table 2) and a partial duplication of chromosome $\mathrm{X}$ with mental retardation (patient 2; Table 2), respectively. The third was not a native Dutch speaker (patient 5; Table 2). 


\section{Conclusions}

In this cohort of survivors of neonatal ECMO the prevalence of SNHL was $8.8 \%$ which approximated that of larger series in the United States. Overall, these children demonstrated normal language development and intelligence, and children with $\mathrm{HL}$ did not perform worse. In addition to the common practice of neonatal hearing screening and audiological follow-up of patients with severe birth asphyxia or (neonatal) meningitis, we suggest that adequate information for parents and caregivers and close follow-up of all children after neonatal ECMO treatment is important. Prompt referral to an ENT-department with expertise in profound audiological evaluation in children should be considered even at minor signals suspicious of hearing impairment.

Acknowledgements

Ko Hagoort provided highly appreciated editorial advice. 
List of abbreviations

BOS 2-30: Bayley Developmental Scales

BSID-II-NL: Bayley Scales of Infant Development - Second Edition - Dutch version

$\mathrm{CDH}$ : congenital diaphragmatic hernia

CLD: chronic lung disease

ECMO: extracorporeal membrane oxygenation

$\mathrm{HL}$ : hearing loss

$\mathrm{IQ}$ : intelligence quotient

MAP: mean airway pressure

MAS: meconium aspiration syndrome

Ol: oxygenation index

PPHN: persistent pulmonary hypertension of the newborn

RAKIT: Revised Amsterdam Intelligence Test

SNHL: sensorineural hearing loss

VA: veno-arterial

VV: veno-venous 


\section{References}

1. Bartlett RH, Andrews AF, Toomasian JM, et al. Extracorporeal membrane oxygenation for newborn respiratory failure: forty-five cases. . Surgery 1982;92:425-433.

2. McNally H, Bennett CC, Elbourne D, et al. United Kingdom collaborative randomized trial of neonatal extracorporeal membrane oxygenation: follow-up to age 7 years. Pediatrics 2006;117(5):e845-854.

3. Lasky RE, Wiorek L, Becker TR. Hearing loss in survivors of neonatal extracorporeal membrane oxygenation (ECMO) therapy and high-frequency oscillatory (HFO) therapy. J Am Acad Audiol 1998;9(1):47-58.

4. Mann T, Adams K. Sensorineural hearing loss in ECMO survivors. . J Am Acad Audiol 1998;9(5):367-370.

5. Sweitzer RS, Lowry JK, Georgeson KE, et al. Hearing loss associated with neonatal ECMO: a clinical investigation. Int J Pediatr Otorhinolaryngol 1997;41(3):339-345.

6. Cheung PY, Robertson CM. Sensorineural hearing loss in survivors of neonatal extracorporeal membrane oxygenation. Pediatr Rehabil 1997;1(2):127-130.

7. Fligor $\mathrm{BJ}, \mathrm{Neault} \mathrm{MW}$, Mullen $\mathrm{CH}$, et al. Factors associated with sensorineural hearing loss among survivors of extracorporeal membrane oxygenation therapy. Pediatrics 2005;115(6):15191528.

8. Kountakis SE, Skoulas I, Phillips D, et al. Risk factors for hearing loss in neonates: a prospective study. Am J Otolaryngol 2002;23(3):133-137.

9. Hille ET, van Straaten HI, Verkerk PH, et al. Prevalence and independent risk factors for hearing loss in NICU infants. Acta Paediatr 2007;96(8):1155-1158.

10. Murray M, Nield T, Larson-Tuttle C, et al. Sensorineural hearing loss at 9-13 years of age in children with a history of neonatal extracorporeal membrane oxygenation. Arch Dis Child Fetal Neonatal Ed 2011;96(2):F128-132.

11. Coenraad S, Goedegebure A, van Goudoever JB, et al. Risk factors for sensorineural hearing loss in NICU infants compared to normal hearing NICU controls. Int J Pediatr Otorhinolaryngol 2010;74(9):999-1002.

12. Grether $\mathrm{S}$. The importance of evaluating language in children with severe to profound sensorineural hearing loss. Dev Med Child Neurol 2010;52(9):791-792.

13. Korver AM, Konings S, Dekker FW, et al. Newborn hearing screening vs later hearing screening and developmental outcomes in children with permanent childhood hearing impairment. JAMA 2010;304(15):1701-1708.

14. Vohr B, Jodoin-Krauzyk J, Tucker R, et al. Early language outcomes of early-identified infants with permanent hearing loss at 12 to 16 months of age. Pediatrics 2008;122(3):535-544.

15. Yoshinaga-Itano C. Early intervention after universal neonatal hearing screening: impact on outcomes. Ment Retard Dev Disabil Res Rev 2003;9(4):252-266.

16. Desai S, Kollros PR, Graziani $L$, et al. Sensitivity and specificity of the neonatal brain-stem auditory evoked potential for hearing and language deficits in survivors of extracorporeal membrane oxygenation. J Pediatr 1997;131(2):233-239.

17. Stolar CJ, Snedecor SM, Bartlett RH. Extracorporeal membrane oxygenation and neonatal respiratory failure: experience from the extracorporeal life support organization. J Pediatr Surg 1991;26(5):563-571.

18. Hofhuis $\mathrm{W}$, Hanekamp MN, ljsselstijn $\mathrm{H}$, et al. Prospective longitudinal evaluation of lung function during the first year of life after extracorporeal membrane oxygenation. Pediatr Crit Care Med 2010. 
19. Hanekamp MN, Mazer P, van der Cammen-van Zijp MH, et al. Follow-up of newborns treated with extracorporeal membrane oxygenation: a nationwide evaluation at 5 years of age. Crit Care 2006;10(5):R127.

20. Jobe AH, Bancalari E. Bronchopulmonary dysplasia. Am J Respir Crit Care Med 2001;163(7):1723-1729.

21. Van der Meulen BF, Smrkovsky M. Handleiding van de Bayley Ontwikkelingsschalen (BOS 230). Lisse: Swets \& Zeitlinger; 1983.

22. Ruiter S, Spelberg H, van der Meulen B, et al. The BSID-II-NL: construction, standardisation, and instrumental utility. Netherlands Journal of Psychology 2008;64(1):15-40.

23. Morini F, Capolupo I, Masi R, et al. Hearing impairment in congenital diaphragmatic hernia: the inaudible and noiseless foot of time. J Pediatr Surg 2008;43(2):380-384.

24. Robertson CM, Cheung PY, Haluschak MM, et al. High prevalence of sensorineural hearing loss among survivors of neonatal congenital diaphragmatic hernia. Western Canadian ECMO Followup Group. Am J Otol 1998;19(6):730-736.

25. Mehra S, Eavey RD, Keamy DG, Jr. The epidemiology of hearing impairment in the United States: newborns, children, and adolescents. Otolaryngol Head Neck Surg 2009;140(4):461-472.

26. Cone BK, Wake $\mathrm{M}$, Tobin $\mathrm{S}$, et al. Slight-mild sensorineural hearing loss in children: audiometric, clinical, and risk factor profiles. Ear Hear 2010;31(2):202-212.

27. Zanchetta S, Resende LA, Bentlin MR, et al. Conductive hearing loss in children with bronchopulmonary dysplasia: a longitudinal follow-up study in children aged between 6 and 24 months. Early Hum Dev 2010;86(6):385-389.

28. Engel J, Mahler E, Anteunis L, et al. Why are NICU infants at risk for chronic otitis media with effusion? Int J Pediatr Otorhinolaryngol 2001;57(2):137-144.

29. Schumacher RE, Palmer TW, Roloff DW, et al. Follow-up of infants treated with extracorporeal membrane oxygenation for newborn respiratory failure. Pediatrics 1991;87(4):451457.

30. Glass $\mathrm{P}$, Wagner AE, Papero PH, et al. Neurodevelopmental status at age five years of neonates treated with extracorporeal membrane oxygenation. J Pediatr 1995;127(3):447-457.

31. Morando C, Midrio P, Gamba P, et al. Hearing assessment in high-risk congenital diaphragmatic hernia survivors. Int J Pediatr Otorhinolaryngol 2010;74(10):1176-1179.

32. Kawashiro N, Tsuchihashi N, Koga K, et al. Delayed post-neonatal intensive care unit hearing disturbance. Int J Pediatr Otorhinolaryngol 1996;34(1-2):35-43.

33. Rollins MD, Hubbard A, Zabrocki L, et al. Extracorporeal membrane oxygenation cannulation trends for pediatric respiratory failure and central nervous system injury. J Pediatr Surg 2012;47(1):68-75.

34. Fukuda $S$, Aoyama $M$, Yamada $Y$, et al. Comparison of venoarterial versus venovenous access in the cerebral circulation of newborns undergoing extracorporeal membrane oxygenation. Pediatr Surg Int 1999;15(2):78-84.

35. Bess FH, Tharpe AM. Unilateral hearing impairment in children. Pediatrics 1984;74(2):206-

216.

36. Davis JM, Elfenbein J, Schum R, et al. Effects of mild and moderate hearing impairments on language, educational, and psychosocial behavior of children. J Speech Hear Disord 1986;51(1):53-62. 
Figure legends

Figure 1:

Flow chart.

$\mathrm{CDH}=$ congenital diaphragmatic hernia 
262 children on ECMO between

January 1992 and February 2005

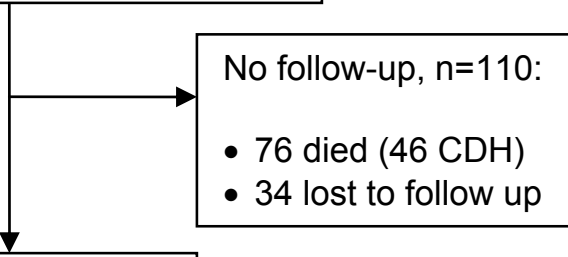

152 children eligible

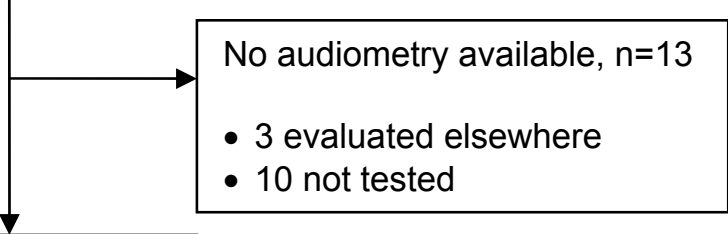

139 children tested

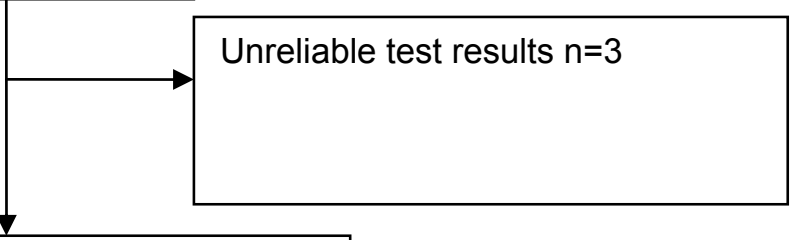

136 children with reliable audiometry

measurements included 
